\title{
Experimental and modeling study of wettability alteration through seawater injection in limestone: a case study
}

\author{
Omolbanin Seiedi ${ }^{1,3} \cdot$ Mohammad Zahedzadeh $^{1,4} \cdot$ Emad Roayaei $^{1} \cdot$ Morteza Aminnaji $^{2,5} \cdot$ Hossein Fazeli $^{2,6}$
}

Received: 18 February 2019 / Published online: 9 January 2020

(c) The Author(s) 2020

\begin{abstract}
Water flooding is widely applied for pressure maintenance or increasing the oil recovery of reservoirs. The heterogeneity and wettability of formation rocks strongly affect the oil recovery efficiency in carbonate reservoirs. During seawater injection in carbonate formations, the interactions between potential seawater ions and the carbonate rock at a high temperature can alter the wettability to a more water-wet condition. This paper studies the wettability of one of the Iranian carbonate reservoirs which has been under Persian Gulf seawater injection for more than 10 years. The wettability of the rock is determined by indirect contact angle measurement using Rise in Core technique. Further, the characterization of the rock surface is evaluated by molecular kinetic theory (MKT) modeling. The data obtained from experiments show that rocks are undergoing neutral wetting after the aging process. While the wettability of low permeable samples changes to be slightly water-wet, the wettability of the samples with higher permeability remains unchanged after soaking in seawater. Experimental data and MKT analysis indicate that wettability alteration of these carbonate rocks through prolonged seawater injection might be insignificant.
\end{abstract}

Keywords Wettability $\cdot$ Carbonate rock $\cdot$ Seawater injection $\cdot$ Dynamic contact angle $\cdot$ Rise in Core $\cdot$ Molecular kinetic theory

\section{Introduction}

More than $60 \%$ of the world's oil in place is located in the Middle East, with over $70 \%$ being reserved in carbonate formations. Seawater flooding has been commonly used in secondary oil recovery as seawater is a feasible and practical water source for reservoir pressure maintenance.

Edited by Yan-Hua Sun

Omolbanin Seiedi

baninseiedi@gmail.com

Mohammad Zahedzadeh

mohammad.zahedzadeh@gmail.com

Emad Roayaei

Emad.roayaei@gmail.com

Morteza Aminnaji

morteza.aminnaji@manchester.ac.uk

Hossein Fazeli

hossein.fazeli@geo.uio.no

1 Improved Oil Recovery Institute, National Iranian Oil

Company (NIOC), Tehran 1969813771, Iran
Several studies have demonstrated that seawater injection can change the wettability of carbonate rocks to more water-wet conditions, where brine composition, oil chemistry, rock lithology, and temperature play significant roles in wettability alteration of rocks during water flooding. Salinity and ions in the injected brine control the wetting state of rocks in the secondary and tertiary oil recovery. In fact, the interaction between brine and crude oil compositions and also the chemicals used in EOR methods are crucial to alter

2 Institute of Petroleum Engineering, University of Tehran, P.O. Box 11155-4563, Tehran, Iran

3 Present Address: Sharif Upstream Petroleum Research Institute (SUPRI), Sharif University of Technology, Tehran, Iran

4 Present Address: Research Institute of Petroleum Industry (RIPI), Tehran, Iran

5 Present Address: School of Chemical Engineering and Analytical Science, University of Manchester, Manchester, UK

6 Present Address: Geochemistry Research Group, University of Nottingham, University Park, Nottingham, UK 
the wettability of carbonate formations (Bera et al. 2017; Pal et al. 2018; Heydari et al. 2019). Hognesen et al. (2005) found that increasing sulfate ions in seawater resulted in an additional oil recovery in carbonate cores (chalk and limestone) at high temperatures. However, the success of this strategy is restricted to the temperature and the salinity of water due to the possibility of scale formation and sulfate-reducing bacteria (SRB) problems (Webb et al. 2005). Experimental studies showed that potential-determining ions in seawater, $\mathrm{Ca}^{2+}, \mathrm{Mg}^{2+}$, and $\mathrm{SO}_{4}^{2-}$, have a great influence on wetting characteristics of carbonate rocks toward water wetting and their efficiency increased at high temperatures (Austad et al. 2005; Zhang and Austad 2006; Strand et al. 2006). Adsorption of sulfate ions in seawater onto chalk surfaces expedited the chemical process of wettability alteration (Strand et al. 2003). Spontaneous imbibition and forced fluid displacement results revealed that seawater is more effective in enhancing oil recovery than the injection of brine free of sulfate ions at temperatures higher than $100{ }^{\circ} \mathrm{C}$ (Zhang et al. 2007; Austad et al. 2008; Strand et al. 2008; Alotaibi et al. 2010). The results of field experience confirmed that the oil recovery in both spontaneous imbibition and forced displacement of injecting seawater were improved. According to the capillary pressure curves, the water wetting characteristics of rocks exposed to seawater increased more than samples treated with formation water (Webb et al. 2005). The effect of injecting seawater as a secondary recovery method was broadly investigated using fluids and rocks of North Sea carbonate fields. Since the levels of potential-determining ions in seawater and crude oil composition are different from place to place, the wetting condition of the Middle East carbonate oil fields was slightly changed after seawater flooding (Alotaibi et al. 2010; Okasha 2014; Zhu et al. 2016).

The oil recovery from carbonate reservoirs is significantly controlled by their wettability which determines the location, distribution, and displacement of reservoir fluids in porous media. Therefore, reliable data of wettability result in more precise prediction of oil recoveries under different injection scenarios, particularly water flooding and EOR techniques (Cuiec 1984; Anderson 1987). The commonly used techniques to determine the wettability of rocks include Amott and USBM (United States Bureau and Mines) methods which are time-consuming and costly. In addition, USBM and Amott tests are not sensitive under mixed/fractional and neutral-wet conditions. Direct contact angle measurement is widely used to define the wettability of smooth pure minerals (Anderson 1986). However, the reservoir rock is comprised of various mineral compositions, and pure mineral crystals are only partially representative of reservoir rocks. Further, the heterogeneity of the rock surface compromises the accuracy of the direct measurement of the contact angle (Morrow 1991).

The Rise in Core (RIC) is a quantitative technique to evaluate the wettability of a solid surface in a contact angle term. This technique is based on modified Washburn and spontaneous liquid imbibition into porous media. Wettability of powders (Siebold et al. 2000; DangVu and Hupka 2005; Yildiz et al. 2010) and heterogeneous reservoir rocks (Ghedan et al. 2010; Ghedan and Canbaz 2014; Aminnaji et al. 2015; Canbaz and Ghedan 2015) could be measured using the RIC technique. The contact angles obtained from the RIC technique match the results measured with Amott and USBM methods (Ghedan et al. 2010). The advantage of the RIC technique over the direct contact angle measurement is providing wettability resembling the dynamic structure of the reservoir. The relative velocity of a liquid moving across the surface during capillary imbibition can be accounted for the wetting. Empirical and theoretical studies in macroscopic and microscopic scales were conducted in order to clarify the underlying mechanisms in the wetting of solid surfaces (Martic et al. 2003; Bonn et al. 2009; Alotaibi et al. 2010). According to molecular kinetic theory (MKT), the macroscopic behavior of a wetting line is considered as the overall statistics of molecular movements within the three-phase zone, whereby the adsorption or desorption of fluid molecules occurs to or from the solid surface (Blake and Coninck 2002; Blake 2006). Experimental dynamic contact angle data are used to obtain the characteristic parameters defining the wetting properties of a solid surface via curve-fitting in the MKT model (Wu et al. 2017).

The main objectives of this work are listed as follows:

1. This is a case study to evaluate the wettability of one of the Iranian carbonate reservoirs after more than 10 years of injecting seawater.

2. The wettability of core rock samples is defined in the contact angle value using a quick and reliable technique called the RIC technique.

3. The derived statistical data from the MKT model are used to quantitatively explain the wetting state of porous and heterogeneous carbonate rocks.

\section{Materials and methods}

\subsection{Materials}

The rocks used in this work were selected from different depths of a carbonate reservoir. According to the X-ray fluorescence (XRF) result presented in Table 1, the major 
Table 1 XRF results of the carbonate rock samples

\begin{tabular}{lllllllllllll}
\hline Component & $\mathrm{SiO}_{2}$ & $\mathrm{Al}_{2} \mathrm{O}_{3}$ & $\mathrm{Fe}_{2} \mathrm{O}_{3}$ & $\mathrm{CaO}$ & $\mathrm{Na}_{2} \mathrm{O}$ & $\mathrm{K}_{2} \mathrm{O}$ & $\mathrm{MgO}$ & $\mathrm{TiO}_{2}$ & $\mathrm{MnO}_{2}$ & $\mathrm{P}_{2} \mathrm{O}_{5}$ & $\mathrm{SO}_{3}$ & $\mathrm{LOI}$ \\
\hline Mass content, \% & 1.190 & 0.280 & 0.150 & 53.420 & 0.170 & 0.110 & 1.210 & 0.006 & 0.002 & 0.085 & 0.133 & 42.720 \\
\hline
\end{tabular}

LOI is the loss on ignition

component of the carbonate formation is calcite. Table 2 lists the petro-physical properties of core samples used.

Synthetic formation brine and seawater were used in the aging and soaking processes, respectively. Compositions of the formation water and Persian Gulf seawater are listed in Table 3. The salinity of formation brine was about 142,000 mg/L, while it was approximately $34,000 \mathrm{mg} / \mathrm{L}$ for seawater.

Crude oil and $n$-hexane were used as the oil phase in the experiments, and their physical properties are presented in Table 4. The crude oil has an acid number (AN) of about $0.07 \mathrm{mg} \mathrm{KOH} / \mathrm{g}$. The composition of crude oil is summarized in Table 5 .

\subsection{Sample preparation}

The rock samples were cut into small plates and then burnished by an end-face grinder to achieve a flat and relatively smooth surface. The dimensions of the rectangular samples were $2 \mathrm{~cm} \times 1 \mathrm{~cm} \times 0.2 \mathrm{~cm}$. The plates were cleaned with toluene and washed with distilled water. They were then dried at $70{ }^{\circ} \mathrm{C}$ for $24 \mathrm{~h}$. The prepared samples were saturated with formation water for $24 \mathrm{~h}$ at ambient temperature and then aged in crude oil at the reservoir temperature, $109{ }^{\circ} \mathrm{C}$ for 2 weeks. To remove the excess oil from the rock surface after aging, the samples were gently washed with $n$-hexane and then dried. In the next step, the

Table 2 Depth, permeability, and porosity of core plugs

\begin{tabular}{lcccc}
\hline Sample no. & Plug no. & Depth, $\mathrm{m}$ & Permeability, $\mathrm{mD}$ & Porosity, $\%$ \\
\hline 1 & 13 & 3498.02 & $<0.01$ & 1.1 \\
2 & 45 & 3506.25 & 26.0 & 23.4 \\
3 & 56 & 3509.02 & 2.2 & 16.1 \\
4 & 140 & 3530.06 & 8.7 & 20.0 \\
5 & 171 & 3537.75 & 9.7 & 20.2 \\
6 & 256 & 3559.08 & 0.5 & 11.0 \\
\hline
\end{tabular}

aged samples were soaked in seawater at $109{ }^{\circ} \mathrm{C}$ (reservoir temperature) for 1 week.

\subsection{Experimental procedures}

\subsubsection{RIC experiment}

RIC was used for the contact angle measurement based on the Washburn equation. In this technique, the wettability of powders and porous media could be characterized using contact angle measurements in the presence of immiscible liquid/liquid or gas/liquid phases (Dang-Vu and Hupka 2005; Ghedan and Canbaz 2014). Washburn derived an equation for the gas/liquid/rock system to describe the imbibition rate of a liquid into porous media (Dang-Vu and Hupka 2005; Siebold et al. 2000; Wolform et al. 2002). The mass of the imbibed fluid into porous media can be obtained by the Washburn equation (Washburn 1921):

$m^{2}=\left(C \rho^{2} \gamma_{\mathrm{LV}} \cos \theta / \mu\right) t$

where $m$ is the mass of the imbibed liquid into the porous media, $\mathrm{g} ; \rho$ is the density of the imbibed fluid, $\mathrm{g} / \mathrm{cm}^{3} ; \gamma_{\mathrm{LV}}$ is the surface tension between liquid and vapor phase, dyne/ $\mathrm{cm} ; \theta$ is the contact angle, ${ }^{\circ} ; \mu$ is the viscosity of the imbibed fluid, $\mathrm{cP} ; t$ is time, $\mathrm{s}$; and $C$ is a constant characterization of the porous medium.

Table 4 Physical properties of fluids used in the RIC experiments

\begin{tabular}{llll}
\hline Liquids & $\begin{array}{l}\text { Density @ } \\
15.6{ }^{\circ} \mathrm{C}, \mathrm{g} / \mathrm{cm}^{3}\end{array}$ & $\begin{array}{l}\text { Viscosity @ } \\
23{ }^{\circ} \mathrm{C}, \mathrm{cP}\end{array}$ & $\begin{array}{l}\text { Surface ten- } \\
\text { sion, dyne/ } \\
\mathrm{cm}\end{array}$ \\
\hline Crude oil & 0.864 & 1.500 & - \\
$n$-Hexane & 0.655 & 2.940 & 18.43 \\
Seawater & 0.998 & 1.002 & 72.80 \\
\hline
\end{tabular}

Table 3 Compositions of the synthetic formation brine and seawater

\begin{tabular}{|c|c|c|c|c|c|c|c|c|}
\hline \multirow[t]{2}{*}{ Water } & \multirow[t]{2}{*}{ Salinity, mg/L } & \multicolumn{7}{|c|}{ Concentration, $\mathrm{mg} / \mathrm{L}$} \\
\hline & & $\mathrm{Na}^{+}$ & $\mathrm{Ca}^{2+}$ & $\mathrm{Mg}^{2+}$ & $\mathrm{Sr}^{2+}$ & $\mathrm{Cl}^{-}$ & $\mathrm{HCO}_{3}^{-}$ & $\mathrm{SO}_{4}^{2-}$ \\
\hline Seawater & 34,000 & 12,000 & 440 & 1632 & - & 21,410 & 166 & 3110 \\
\hline Formation brine & 142,000 & 52,000 & 7400 & 936 & 1311 & 88,252 & 300 & 242 \\
\hline
\end{tabular}


Table 5 Dead oil composition

\begin{tabular}{llllllllllllll}
\hline Composition & $\mathrm{C}_{3}$ & $i-\mathrm{C}_{4}$ & $n-\mathrm{C}_{4}$ & $i-\mathrm{C}_{5}$ & $n-\mathrm{C}_{5}$ & $\mathrm{C}_{6}$ & $\mathrm{C}_{7}$ & $\mathrm{C}_{8}$ & $\mathrm{C}_{9}$ & $\mathrm{C}_{10}$ & $\mathrm{C}_{11}$ & $\mathrm{C}_{12}$ & $\mathrm{C}_{12+}$ \\
\hline Mole fraction, mol\% & 0.195 & 0.210 & 0.987 & 1.560 & 2.480 & 6.740 & 12.290 & 13.780 & 9.090 & 7.020 & 5.860 & 5.070 & 34.710 \\
\hline
\end{tabular}

In RIC experiments, $C$ and $\theta$ are unknown parameters. The parameter $C$ for each sample is measured using a reference imbibition liquid, particularly an alkane with low surface tension; therefore, its contact angle is assumed to be zero and it completely wets the rock surface. The slope of the squared mass of the imbibed liquid versus time is used to calculate $C$, and the contact angle of the air/liquid/rock system can be calculated for different liquids by $C$ of each sample.

RIC experiments were performed using a Sigma 700 tensiometer at ambient temperature as shown in Fig. 1a. The schematic view of the experimental setup is presented in Fig. 1b. The setup is composed of a high precision balance with a weighting accuracy of $0.01 \mathrm{mg}$. The samples were hung from a hook under the balance during the experiments. The samples were held vertically at a fixed position, while the container of liquid could move up and down. In the beginning, the container of liquid was moved up until the bottom of the sample barely touched the liquid and then it was kept fixed. Mass changes were continuously recorded over a period of time, and plots of the squared mass of imbibed liquid versus time were generated.

\subsubsection{MKT model}

Based on the MKT definition, the wetting line depends on the statistical dynamics of the molecules within a zone where solid, liquid, and gas phases meet; then, the adsorption prevents liquid molecules to freely slip across a solid surface. According to the model, the contact line moves when the driving force overcomes the energy barriers and promotes molecular displacements (Blake 2006). The key parameters for solid surface interpretation are $\lambda, k_{\mathrm{w}}^{0}$, and $n$; where $\lambda$ is the average distance between the adsorption sites on the solid surface, $k_{\mathrm{w}}^{0}$ denotes the frequency of the molecular displacement at the equilibrium state, and $n$ represents the number of adsorption sites per unit area of the solid surface. Blake and Haynes assumed that the driving force to move the wetting line in a specific direction is the unbalanced surface tension force, $\gamma_{\mathrm{LV}}\left(\cos \theta_{0}-\cos \theta\right)$, where $\gamma_{\mathrm{LV}}$ is the surface tension of the liquid/vapor, dyne/ $\mathrm{cm} ; \theta_{0}$ is the static contact angle, degree and $\theta$ is the dynamic contact angle, degree (Blake and Haynes 1969).

Using the Frenkel-Eyring activated-rate theory (Glastone et al. 1941; Powell et al. 1941; Frenkel 1946), the relationship between velocity, $v$, and dynamic contact angle, $\theta$, could be defined by Eq. (2):

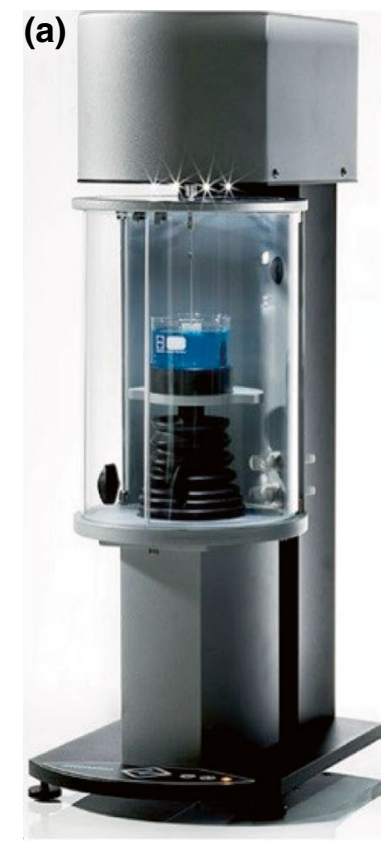

(b)

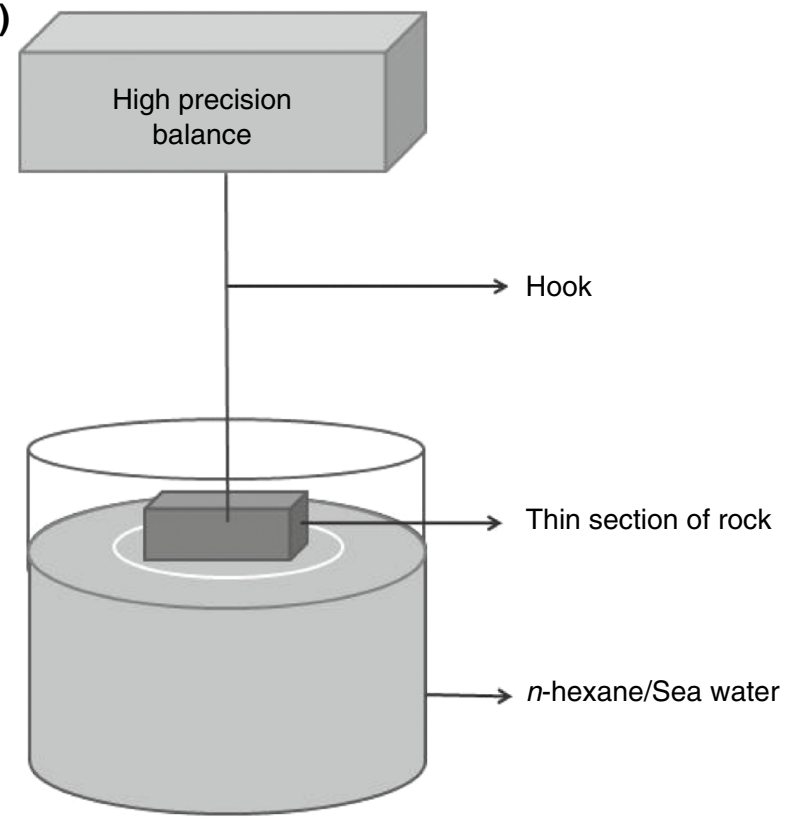

Fig. 1 a Sigma 700 tensiometer. b Schematic diagram of the experimental setup for RIC experiments 
$v=2 k_{\mathrm{w}}^{0} \lambda \sinh \left[\left(\frac{\gamma_{\mathrm{LV}}}{2 n k_{\mathrm{B}} T}\right)\left(\cos \theta_{0}-\cos \theta\right)\right]$

where $k_{\mathrm{B}}$ is the Boltzmann constant and $T$ is the absolute temperature. Thus, there are three unknown molecular parameters: $n, \lambda$, and $k_{\mathrm{w}}^{0}$ which can be obtained from tuning the model parameters based on experimental data (de Ruijter et al. 1999).

Dynamic contact angle measurements were carried out at different velocities with the Sigma 700 tensiometer in order to deduce the rock characteristics using the MKT model. The Sigma 700 tensiometer was to measure the advancing and receding contact angles using the Wilhelmy plate method (Aminnaji et al. 2015). Based on this method, a sensitive balance was used to measure the force exerted by the liquid on the solid when the liquid container moved upward and downward. In the beginning, the container was moved upward to measure the advancing contact angle and when the bottom of the plate reached the specific immersion depth, the container was moved downward at the same speed to measure the receding contact angle. The wetting force was calculated based on Eq. (3), and then the dynamic contact angle was measured at various speeds

$F_{\text {total }}=F_{\text {wetting }}+F_{\text {weight of probe }}-F_{\text {buoyancy }}$

$F_{\text {wetting }}=\gamma_{\mathrm{LV}} P \cos \theta$

where $P$ is the perimeter of the plate and $\theta$ is the advancing or receding contact angle.

\section{Results and discussion}

\subsection{Results of RIC experiments}

In the first step, the constant characterization of the rock sample was evaluated by performing RIC experiments with an $n$-hexane/air/rock system. The rock sample became strongly wet with $n$-hexane in the presence of air due to very low surface tension, $\gamma_{n \text {-hexane }}=18.43 \mathrm{mN} / \mathrm{m}$. This suggests that the contact angle is assumed to be zero in Eq. (1). The slope of the curve, $\Delta m^{2} / t$, obtained from RIC experiments was used to calculate the constant characterization of the sample, $C$.

The curve of $n$-hexane imbibition into the aged sample 1 (plug 13) is presented in Fig. 2. The slope of the curve is $\Delta m^{2} / t=1 \times 10^{-8} \mathrm{~g}^{2} / \mathrm{s}$, and the constant $C$ is about $3.72 \times 10^{-7}$ with $R^{2}=0.9986$. The constant $C$ of each sample remains nearly constant after soaking in seawater.

The next step was to measure the wettability of the sample by determining the contact angle in the air/seawater/ rock system with a known constant $C$. The start time, $t=0$,

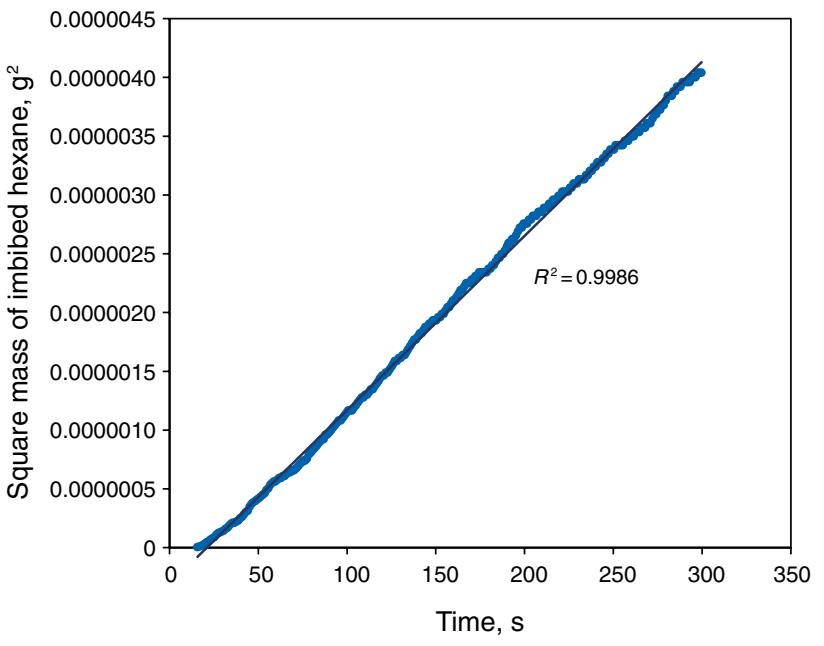

Fig. 2 RIC results for a system of air/ $n$-hexane/sample 1

began when the rock touched the liquid surface. Figure $3 \mathrm{a}$ displays the seawater imbibition into sample 1 after aging in crude oil, where the linear slope is $\Delta m^{2} / t=1 \times 10^{-8} \mathrm{~g}^{2} / \mathrm{s}$ with $R^{2}=0.998$. According to the physical properties of seawater and constant $C$, the contact angle of the aged sample 1 was determined to be around $\theta=89.9^{\circ}$. The wettability of the sample after soaking in seawater was measured in the same way. Two distinct curves for sample 1, after aging in crude oil and soaking in seawater, were compared as shown in Fig. 3b. The contact angle of the sample became $70.5^{\circ}$ after soaking in seawater.

The water imbibition curves of sample 1 after aging in crude oil and soaking in seawater are presented in Fig. 4. Wettability modification can be deduced from rapid spontaneous imbibition of water into porous media (Hognesen et al. 2006). The imbibition rate of a liquid into the rock sample depends on capillary and gravity forces, where wettability plays a significant role in the spontaneous imbibition process. Rapid seawater imbibition occurs due to a high capillary force if the rock is water-wet. In the beginning, water enters pores due to the capillary force and rises until the capillary force gets balanced with the gravity force. The greater capillary force leads to faster water imbibition, and therefore the porous media will be filled sooner. According to the penetrating liquid curves, there are different trends of seawater imbibition into sample 1 before and after soaking in seawater. Water imbibition into the aged sample increased almost linearly over the time period shown, while there were two discrete regions for the soaked sample; water imbibed quickly to reach a plateau and then remained constant. Furthermore, the amount of water is approximately 7 times higher if the sample is soaked in seawater; it is about $0.035 \mathrm{~g}$ for the soaked sample, but only $0.005 \mathrm{~g}$ for the aged sample. Dang-Vu and Hupka found that the liquid imbibition in porous media occurs through two steps: first, the liquid 

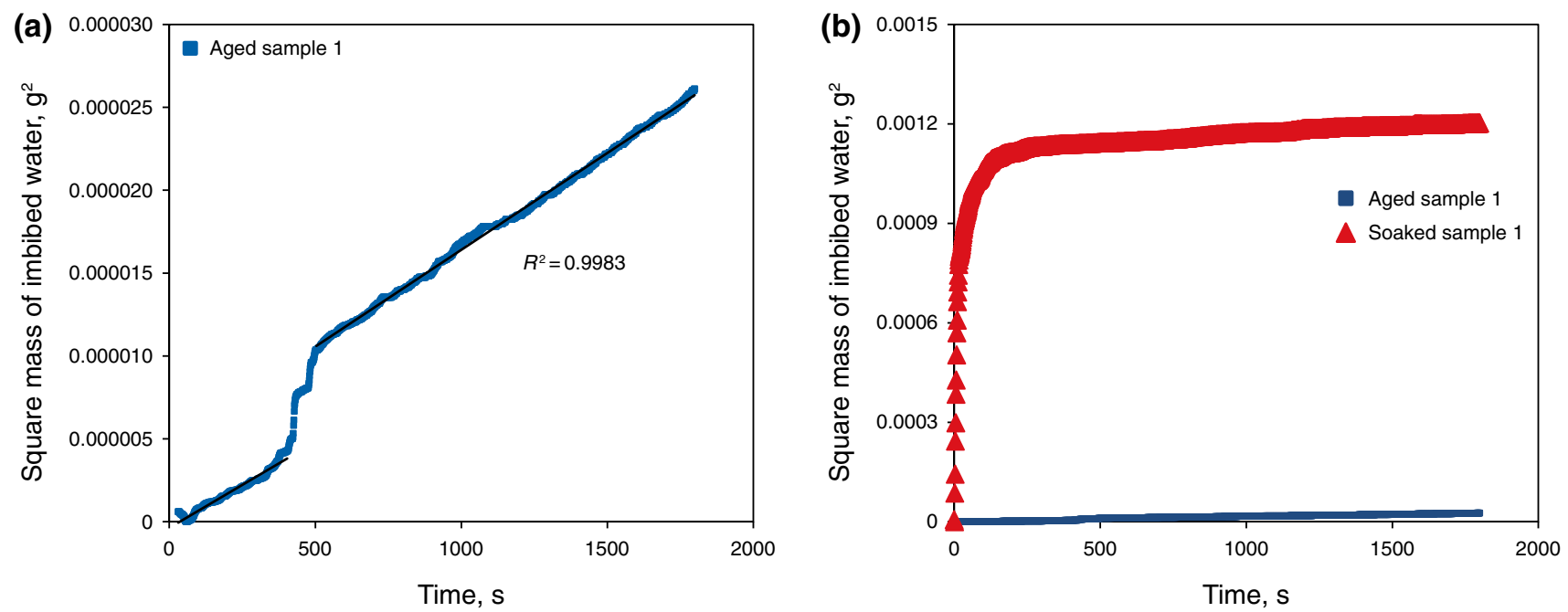

Fig. 3 RIC results of a aged sample 1, b a comparison of sample 1 before and after soaking in seawater

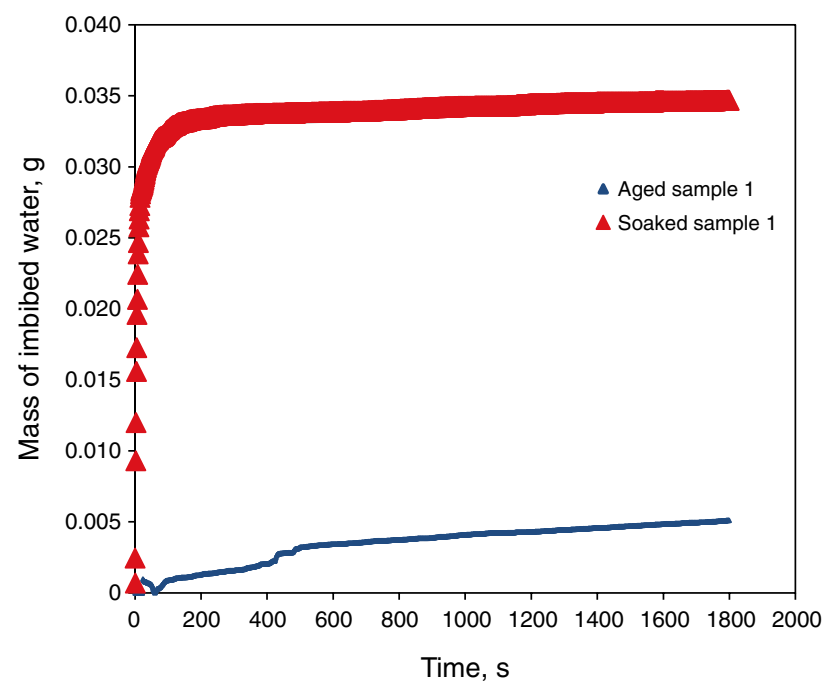

Fig. 4 Seawater imbibition curve of sample 1

Table 6 Contact angles of samples obtained from RIC experiments

\begin{tabular}{lll}
\hline Sample no. & \multicolumn{2}{l}{ Contact angle, degree } \\
\cline { 2 - 3 } & Aged sample & Soaked sample \\
\hline 1 & 89.9 & 70.5 \\
2 & 89.3 & 82.8 \\
3 & 86.8 & 84.5 \\
4 & 89.9 & 88.8 \\
5 & 89.7 & 87.0 \\
6 & 89.6 & 78.0 \\
\hline
\end{tabular}

occupies pores due to the wetting condition, so the mass of the liquid rises until it reaches a constant value during penetration, and then the liquid fills the whole pores and saturation takes place (Dang-Vu and Hupka 2005). The time required to reach saturation mainly depends on the wettability of porous media. The results suggested that the saturation process in the soaked sample 1 occurred sooner in response to more water-wet condition.

The contact angles for all samples are summarized in Table 6. The initial contact angle of each sample is in the range of $86^{\circ}-90^{\circ}$ which means that aged samples are neutral-wet. After soaking in seawater, the contact angles of four samples (samples 2-5) slightly changed and just two other samples displayed more wettability change.

Figure 5 illustrates the contact angle measured by RIC experiments versus layer depth of the samples according to the wettability criteria (Anderson 1986; Chilinger and Yen 1983). As can be seen, the aged samples were neutral-wet with contact angle in the range of $86^{\circ}-90^{\circ}$. When the samples were exposed to seawater, the wettability of samples 1 and 6 (low permeability core samples) changed to a slightly water-wet condition, while the other samples revealed a negligible change and remained neutral-wet. The results suggest that seawater may slightly change the wettability of carbonate rocks which are consistent with the findings reported in other studies (van Oss 1994; Okasha 2014; Zhu et al. 2016). In addition, the results indicate that the low permeable samples (samples 1 and 6) changed to slightly water-wet after soaking in seawater, but the wettability of high permeability core samples did not change. 


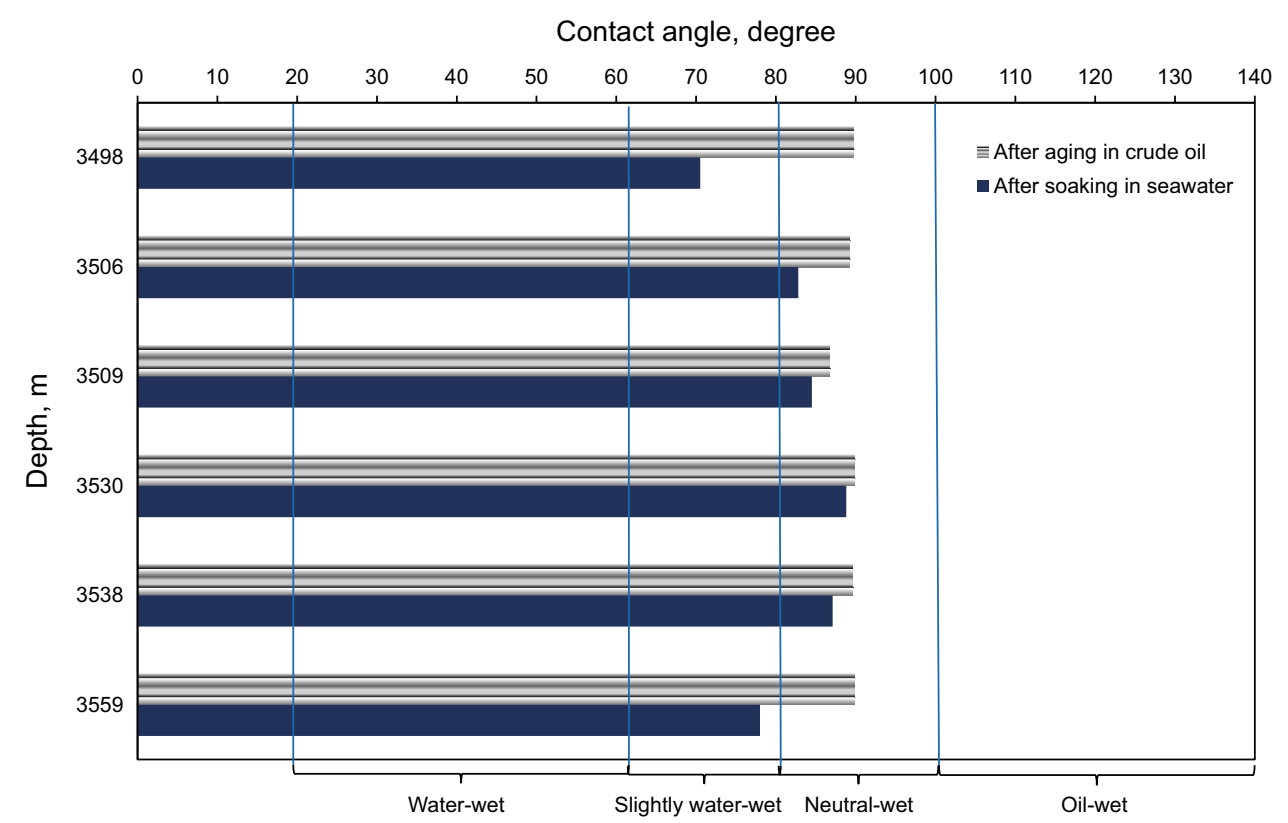

Fig. 5 Wettability of carbonate rock samples before and after soaking in seawater
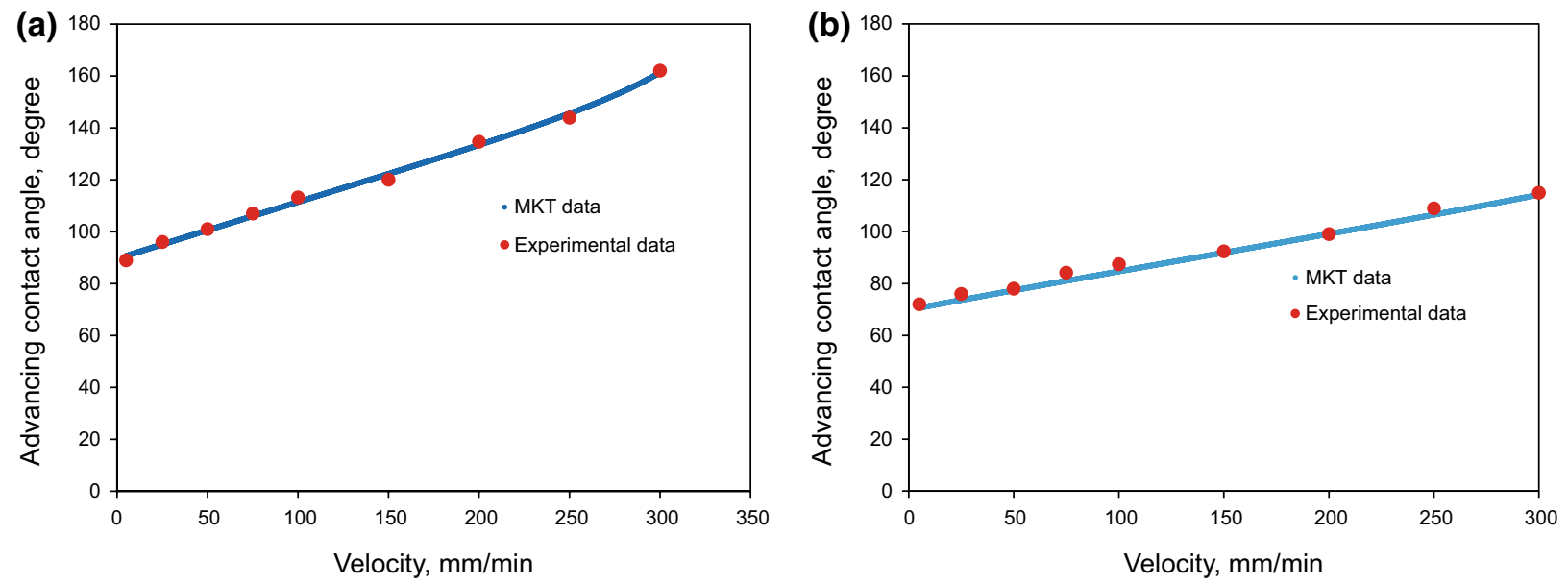

Fig. 6 Advancing contact angle versus contact line velocity of water and fitted model for sample 1 after a aging in crude oil, b soaking in seawater

\subsection{Results of the MKT model}

The dynamic contact angles at various speeds were measured using the Sigma 700 tensiometer, and the G-dyna software, special software for dynamic wetting theory, was used to derive the parameters of the MKT model by curve-fitting. The molecular parameters of $n, \lambda$, and $k_{\mathrm{w}}^{0}$ were obtained based on Eq. (2) (Seveno et al. 2009).

Figure 6 demonstrates the dynamic advancing contact angles and curve-fittings for sample 1 after aging in crude oil and soaking in seawater. The MKT model properly fitted the experimental dynamic contact angle data for the aged sample with a characteristic length, $\lambda=0.37 \mathrm{~nm}$, and a displacement frequency at equilibrium, $k_{\mathrm{w}}^{0}=4.7 \mathrm{MHz}$. The same fitting procedure was applied to the core sample after soaking in seawater with $\lambda=6 \times 10^{-4} \mathrm{~nm}$ and $k_{\mathrm{w}}^{0}=1.7 \times 10^{10} \mathrm{MHz}$.

Table 7 reports the MKT parameters for all samples before and after soaking in seawater, which was obtained from the curve-fitting, as well as the corresponding errors. It is clear that the parameters $\lambda, n$, and $k_{\mathrm{w}}^{0}$ for all aged samples are in the same order of magnitude. Once treated with seawater, samples 1, 2 and 6 show significant changes with similar trends; the average distance between the adsorption 
Table 7 MKT parameters obtained by curve-fitting of the MKT model

\begin{tabular}{|c|c|c|c|c|c|c|c|}
\hline & Condition (state) & Sample 1 & Sample 2 & Sample 3 & Sample 4 & Sample 5 & Sample 6 \\
\hline \multirow[t]{2}{*}{$\lambda, \mathrm{nm}$} & After aging in crude oil & 0.370 & 0.433 & 0.470 & 0.510 & 0.460 & 0.390 \\
\hline & After soaking in seawater & $0.06 \times 10^{-2}$ & $0.2 \times 10^{-2}$ & 0.48 & 0.57 & 0.51 & 0.27 \\
\hline \multirow[t]{2}{*}{$n, \mathrm{~nm}^{-2}$} & After aging in crude oil & 7.30 & 5.35 & 4.50 & 3.90 & 4.76 & 6.54 \\
\hline & After soaking in seawater & $2.7 \times 10^{6}$ & $2.4 \times 10^{5}$ & 4.3 & 3.1 & 3.7 & 14.0 \\
\hline \multirow[t]{2}{*}{$k_{\mathrm{w}}^{0}, \mathrm{MHz}$} & After aging in crude oil & 4.70 & 1.50 & 0.85 & 0.66 & 1.56 & 2.50 \\
\hline & After soaking in seawater & $1.7 \times 10^{10}$ & $3.3 \times 10^{7}$ & 1.17 & 0.87 & 1.50 & 20.50 \\
\hline \multirow[t]{2}{*}{$\theta_{0}$, degree } & After aging in crude oil & 89.4 & 86.0 & 84.5 & 84.4 & 88.4 & 85.0 \\
\hline & After soaking in seawater & 69.9 & 79.2 & 84.0 & 84.3 & 85.5 & 80.6 \\
\hline \multirow[t]{2}{*}{ Error $E_{\mathrm{r}}, \%$} & After aging in crude oil & 1.3 & 3.6 & 4.4 & 2.9 & 1.4 & 3.6 \\
\hline & After soaking in seawater & 1.10 & 1.40 & 2.50 & 0.90 & 1.10 & 1.05 \\
\hline
\end{tabular}

$E_{\mathrm{r}}=\frac{\theta_{\text {calculated }}-\theta_{\text {measured }}}{\theta_{\text {calculated }}} \times 100 \%$

sites on the solid surface, $\lambda$, decreases, and on the other hand, the number of adsorption sites per unit area of the solid surface, $n$, increases several times for these samples. The corresponding parameters of samples 3, 4, and 5 change only slightly.

When the wettability changes to more water-wet, the value of $\lambda$ diminishes which means that the distance between adsorption sites on the rock surface becomes shorter. The same behavior is observed for samples 1 and 2 where the values of $\lambda$ decline from 0.37 and $0.43 \mathrm{~nm}$ to $0.06 \times 10^{-2}$ and $0.2 \times 10^{-2} \mathrm{~nm}$, respectively, while the value of $\lambda$ for sample 6 reaches $0.27 \mathrm{~nm}$. The parameter $\lambda$ for other samples shows a little increase after soaking in seawater.

The value of $n$, the number of active sites per unit area on the surface, increases by changing the wettability to more water-wet. The values of $n$ for samples 1 and 2 increase by several orders of magnitudes from 7.3 to $2.7 \times 10^{6} \mathrm{~nm}^{-2}$ and 5.4 to $2.4 \times 10^{5} \mathrm{~nm}^{-2}$, and for sample 6 , its value reaches twice the initial value $\left(6.54 \mathrm{~nm}^{-2}\right)$. However, a slight reduction in $n$ is observed for samples 3, 4, and 5 .

Wettability alteration to more water-wet condition results in strong bonds of solid and water; therefore, the frequency of the molecular movement called $k_{\mathrm{w}}^{0}$ will decrease due to adhesion of water molecules to the active sites on the solid surface. In all cases, $k_{\mathrm{w}}^{0}$ reveals an increase after soaking in seawater. These results suggest a conflict with two other parameters, particularly for samples 1,2 and 6 .

The MKT fitting curves provide static contact angles of water confirming that the wettability of samples 1,2 and 6 changes to more water-wet, while the wetting of other samples remains unchanged. Sample 1 becomes slightly waterwet as the static contact angle changes from $89.4^{\circ}$ to $69.9^{\circ}$. These results are in good agreement with the contact angles obtained using the RIC experiments considering curve-fitting errors.

\section{Conclusions}

The wetting behavior of carbonate rocks is studied by continuous assessment of seawater imbibition into porous media using the RIC technique. The wetting condition of rocks is also investigated by MKT model with molecular parameters obtained from curve-fitting, $\lambda, n$, and $k_{\mathrm{w}}^{0}$ describing the characteristics of the rock surface on a microscopic scale, and the static contact angle of the rock sample is determined as well.

The following conclusions can be drawn from this study:

- In comparison with conventional methods, the RIC technique takes less time and effort, thanks to these advantages, there is a possibility to study more reservoir core samples in a short time. The average wettability of cores is measured and stated in a contact angle term.

- The experimental dynamic contact angles fit the MKT model very well. There is a good agreement between the static contact angles obtained from two methods.

- Carbonate rocks become neutral-wet after the aging process with measured contact angles of around $90^{\circ}$.

- Seawater can change the wettability of low permeability plugs to more water-wet conditions, while the wetting state of higher permeable plugs remains unchanged.

Acknowledgements This research has been done at Improved Oil Recovery Research Institute of National Iranian Oil Company and Institute of Petroleum Engineering (IPE), The University of Tehran by the financial support of Iranian Offshore Oil Company (IOOC). The authors would like to thank Dr. Alireza Bahramian from Institute of Petroleum Engineering, The University of Tehran and the senior management of IOOC for their help and support.

Open Access This article is licensed under a Creative Commons Attribution 4.0 International License, which permits use, sharing, adaptation, distribution and reproduction in any medium or format, as long as you give appropriate credit to the original author(s) and the source, 
provide a link to the Creative Commons licence, and indicate if changes were made. The images or other third party material in this article are included in the article's Creative Commons licence, unless indicated otherwise in a credit line to the material. If material is not included in the article's Creative Commons licence and your intended use is not permitted by statutory regulation or exceeds the permitted use, you will need to obtain permission directly from the copyright holder. To view a copy of this licence, visit http://creativecommons.org/licenses/by/4.0/.

\section{References}

Alotaibi MB, Nasralla RA, Nasr-El-Din HA. Wettability challenges in carbonate reservoirs. In: SPE improved oil recovery symposium. New York: Society of Petroleum Engineers; 2010. https://doi. org/10.2118/129972-MS.

Aminnaji M, Fazeli H, Bahramian A, Gerami S, Ghojavand H. Wettability alteration of reservoir rocks from liquid wetting to gas wetting using nanofluid. Transp Porous Media. 2015;109(1):201-16. https://doi.org/10.1007/s11242-015-0509-6.

Anderson WG. Wettability literature survey-part 2: wettability measurement. J Pet Technol. 1986;38(11):1246-62. https://doi. org/10.2118/13933-PA.

Anderson WG. Wettability literature survey-part 6: the effects of wettability on water flooding. J Pet Technol. 1987;39(12):1-50. https ://doi.org/10.2118/16471-PA.

Austad T, Strand S, Hognesen EJ, Zhang P. Seawater as IOR fluid in fractured chalk. In: SPE international symposium on oilfield chemistry. New York: Society of Petroleum Engineers; 2005. https ://doi.org/10.2118/93000-MS.

Austad T, Strand S, Madland MV, Puntervold T, Korsnes RI. Seawater in chalk: an EOR and compaction fluid. SPE Reserv Eval Eng. 2008;11(4):648-54. https://doi.org/10.2118/118431-PA.

Bera A, Mandal A, Belhaj H, Kumar T. Enhanced oil recovery by nonionic surfactants considering micellization, surface, and foaming properties. Pet Sci. 2017;14(2):362-71. https://doi.org/10.1007/ s12182-017-0156-3.

Blake TD. The physics of moving wetting lines. J Colloid Interface Sci. 2006;299:1-13. https://doi.org/10.1016/j.jcis.2006.03.051.

Blake TD, Coninck JD. The influence of solid-liquid interactions on dynamic wetting. Adv Colloid Interface Sci. 2002;96:21-36. https ://doi.org/10.1016/S0001-8686(01)00073-2.

Blake TD, Haynes JM. Kinetics of liquid/liquid displacement. J Colloid Interface Sci. 1969;30(3):421-3. https://doi.org/10.1016/00219797(69)90411-1.

Bonn D, Eggers J, Indekeu J, Meunier J, Rolley E. Wetting and spreading. Rev Mod Phys. 2009;81:739-805. https://doi.org/10.1146/ annurev-fluid-011212-140734.

Canbaz CH, Ghedan S. Wettability characterization of different oil/ brine/rock systems by using Rise in Core method. In: 20th international petroleum and natural gas congress and exhibition (IPETGAS). Turkey; 2015. p. 365-70.

Chilinger GV, Yen TF. Some notes on wettability and relative permeabilities of carbonate reservoir rocks. II. Energy Sour. 1983;7(1):67-75. https://doi.org/10.1080/00908318308908076.

Cuiec L. Rock/crude oil interactions and wettability: an attempt to understand their interrelation. In: SPE annual technical conference and exhibition, 16-19 September. Houston; 1984. https:// doi.org/10.2118/13211-MS.
Dang-Vu T, Hupka J. Characterization of porous materials by capillary rise method. Physiochem Probl Miner Process. 2005;39:47-65.

de Ruijter MJ, Blake TD, Coninck J. Dynamic wetting studied by molecular modeling simulations of droplet spreading. Langmuir. 1999;15:7836-47. https://doi.org/10.1021/la9901711.

Frenkel JI. Kinetic theory of liquids. Oxford: Oxford University Press; 1946.

Ghedan SG, Canbaz CH, Boyd D, Mani G, Haggag M. Wettability profile of thick carbonate reservoir by the new Rise in Core wettability characterization method. In: Abu Dhabi international petroleum exhibition and conference. New York: Society of Petroleum Engineers; 2010. https://doi.org/10.2118/138697-MS.

Ghedan SG, Canbaz CH. Theory and experimental setup of the new Rise in Core reservoir wettability measurement technique. In: International petroleum technology conference; 2014. https://doi. org/10.2523/iptc-17659-ms.

Glastone S, Laidler KJ, Eyring H. The theory of rate processes. New York: McGraw-Hill; 1941.

Heydari N, Asgari M, Shojai Kaveh N, Fakhroueian Z. Novel application of PEG/SDS interaction as a wettability modifier of hydrophobic carbonate surfaces. Pet Sci. 2019;16:318-27. https://doi. org/10.1007/s12182-018-0260-z.

Hognesen EJ, Strand S, Austad T. Waterflooding of preferential oilwet carbonates: oil recovery related to reservoir temperature and brine composition. In: SPE Europec/EAGE annual conference. New York: Society of Petroleum Engineers; 2005. https://doi. org/10.2118/94166-MS.

Hognesen EJ, Standnes DC, Austad T. Experimental and numerical investigation of high temperature imbibition into preferential oil-wet chalk. J Petrol Sci Eng. 2006;53(1):100-12. https://doi. org/10.1016/j.petrol.2006.04.002.

Martic G, Coninck JD, Blake TD. Influence of the dynamic contact angle on the characterization of porous media. J Colloid Interface Sci. 2003;263:213-6. https://doi.org/10.1016/S0021 -9797(03)00283-2.

Morrow NR. Interfacial phenomena in petroleum recovery. New York: Surfactant Science Series, Marcel Dekker Inc.; 1991.

Okasha MT. Wettability evaluation of Arabian carbonate reservoir after prolonged water injection: a case study. In: 11 th middle east geosciences conference and exhibition. Middle East; 2014.

Pal S, Mushtaq M, Banat F, Al Sumaiti AM. Review of surfactantassisted chemical enhanced oil recovery for carbonate reservoirs: challenges and future perspectives. Pet Sci. 2018;15:77-102. https ://doi.org/10.1007/s12182-017-0198-6.

Powell RE, Roseveare WE, Eyring H. Diffusion thermal conductivity and viscose flow of liquids. Ind Eng Chem. 1941;33(4):430-5.

Seveno D, Vaillant A, Rioboo R, Adao H, Conti J, Coninck JD. Dynamics of wetting revisited. Langmuir. 2009;25:13032-44. https://doi. org/10.1021/la901125a.

Siebold A, Nardin M, Schultz J, Walliser A, Oppliger M. Effect of dynamic contact angles on capillary rise phenomena. Colloids Surf A. 2000;161:81-7. https://doi.org/10.1016/S0927 -7757(99)00327-1.

Strand S, Standnes DC, Austad T. Spontaneous imbibition of aqueous surfactant solutions into neutral to oil-wet carbonate cores: effects of brine salinity and composition. Energy Fuel. 2003;17(5):113344. https://doi.org/10.1021/ef030051s.

Strand S, Høgnesen EJ, Austad T. Wettability alteration of carbonates-effects of potential determining ions $\left(\mathrm{Ca}^{2+}\right.$ and $\left.\mathrm{SO}_{4}{ }^{2-}\right)$ and temperature. Colloids Surf A. 2006;275:1-10. https://doi. org/10.1016/j.colsurfa.2005.10.061. 
Strand S, Puntervold T, Austad T. Effect of temperature on enhanced oil recovery from mixed-wet chalk cores by spontaneous imbibition and forced displacement using seawater. Energy Fuel. 2008;22:3222-5. https://doi.org/10.1021/ef0800244v.

van Oss CJ. Interfacial forces in aqueous media. New York: Marcel Dekker Inc.; 1994.

Washburn EW. The dynamics of capillary flow. Phys Rev. 1921;17(3):273-83. https://doi.org/10.1103/physrev.17.273.

Webb KJ, Black CJJ, Tjetland G. A laboratory study investigating methods for improving oil recovery in carbonates. In: International petroleum technology conference, 21-23 November. Doha; 2005. https://doi.org/10.2523/IPTC-10506-MS.

Wolform R, Chander S, Hogg R. Evaluation of capillary rise methods for determining wettability of powders. Miner Metall Proc. 2002;19(4):198-202. https://doi.org/10.1007/bf03403269.

Wu P, Nikolov AD, Wasan DT. Capillary rise: validity of the dynamic contact angle models. Langmuir. 2017;33(32):7862-72. https:// doi.org/10.1021/acs.langmuir.7b01762.
Yildiz HO, Oztorun FB, Sirkeci AA. Determination of reservoir rock wettability by thin layer wicking approach. In: SPE/DGS Saudi Arabia section technical symposium and exhibition, 4-7 April. Al-Khobar; 2010. https://doi.org/10.2118/136936-MS.

Zhang P, Austad T. Wettability and oil recovery from carbonates: effects of temperature and potential determining ions. Colloids Surf A. 2006;279:179-87. https://doi.org/10.1016/j.colsu rfa.2006.01.009.

Zhang P, Tweheyo MT, Austad T. Wettability alteration and improved oil recovery by spontaneous imbibition of seawater into chalk: impact of the potential determining ions: $\mathrm{Ca}^{2+}, \mathrm{Mg}^{2+}$, and $\mathrm{SO}_{4}{ }^{2-}$. Colloids Surf A. 2007;301:199-208. https://doi.org/10.1016/j. colsurfa.2006.12.058.

Zhu G, Xu LK, Wang X, Liu F, Cong Y, Zhang Y, Ou J. Enhanced oil recovery by seawater flooding in Halfaya carbonate reservoir, Iraq: experiment and simulation. In: SPE EOR conference at oil and gas West Asia, 21-23 March. Muscat; 2016. https://doi. org/10.2118/179843-MS. 